\section{A consideration of the time taken to do dacryo- cystorhinostomy (DCR) surgery}

\begin{abstract}
Purpose Comparison of surgical times for dacryocystorhinostomy (DCR) by three different approaches: (1) external, (2) endoscopic endonasal surgical (EES), and (3) endoscopic endonasal laser (EEL) using the holmium:YAG laser. The merits and limitations of each approach are considered and surgical throughput predicted.
\end{abstract}

Methods Prospective study of adult patients undergoing primary DCR surgery for nasolacrimal duct obstruction. Surgical times were recorded. Subjective and objective outcomes were assessed at a minimum of 6 months.

Results A total of 48 patients undergoing 51 DCR procedures were studied. The mean surgical time for primary external $(n=20)$, EES-DCR $(n=16)$, and EEL-DCR $(n=15)$ was $41.1 \pm 10.3,39.6 \pm 13.8$, and $20.9 \pm 7.8 \mathrm{~min}$, with symptomatic success achieved in 95, 88, and $60 \%$, respectively. Follow-up was 6-36 months, mean 8 months. It was calculated that if six EEL-DCR, four EES-DCR, or three external DCRs are performed per list for 45 lists per annum, this equals a total of 270 EEL-DCR, 180 EES-DCR, and 135 external DCRs. Of these, 108 EEL-DCR, 22 EES-DCR, and seven external DCRs will fail. If $75 \%$ of these have redo surgery using the same technique, an extra 13.5 (EEL-DCR), four (EES-DCR), and two (external DCR) lists are needed.

Conclusions There was no significant difference between the time taken to do EES-DCR compared to external DCR, and their clinical outcomes. Only EEL-DCR was significantly faster $(P<\mathbf{0 . 0 0 1})$. However, its lower success rate negates the apparent benefit from the greater surgical throughput.

Eye (2003) 17, 691-696. doi:10.1038/

sj.eye. 6700470
R Malhotra ${ }^{1,2}$, M Wright $^{3}$ and JM Olver ${ }^{1}$

Keywords: dacryocystorhinostomy; lacrimal; endonasal; surgical times

\section{Introduction}

Surgery for nasolacrimal duct obstruction has been the subject of newer endoscopic endonasal techniques recently. ${ }^{1-16}$ The perceived disadvantages of the highly successful external approach dacryocystorhinostomy (DCR) $)^{17-21}$ include the risk of cutaneous scar and lengthy surgery with significant blood loss. These reservations have fuelled the popularity of minimally invasive endonasal approaches. Endoscopic endonasal DCR has evolved from functional endoscopic sinus surgery and can be performed either with surgical instruments or using a laser. The advantages of endonasal DCR in comparison with external DCR include no visible scar, minimal blood loss, and quicker surgery, which can often be carried out under local anaesthesia. In particular, the use of the holmium:YAG laser has increased the throughput of lacrimal surgery for many units. ${ }^{11}$ However, success rates for both endoscopic endonasal surgical (EES) ${ }^{4,6,10,16}$ and laser $(\mathrm{EEL})^{5,7,8,11,12,14,16}$ types of DCR are generally lower than for external DCR, ${ }^{9,18-21}$ resulting in more cases that will require secondary surgery.

The aim of this study was to compare the total surgical time taken to perform DCR by three different approaches: external DCR, EES-DCR, and EEL-DCR (holmium:YAG laser). We timed each surgical step to determine as to which ones were limiting rapid surgery. Subjective and objective outcomes - irrigation and functional endoscopic dye test (FEDT) — were both assessed. From the surgical times and the clinical outcomes, we aimed to apply simple mathematical modelling in order to predict the surgical throughput for an oculoplastic/ lacrimal unit.
${ }^{1}$ The Western Eye Hospital Marylebone Road London, UK

${ }^{2}$ Oxford Eye Hospital Walton Street Oxford, UK

${ }^{3}$ Department of Epidemiology and Biostatistics Imperial College London, UK

Correspondence: JM Olver

Western Eye Hospital Marylebone Road London NW1 5YE, UK Tel: + 442078863264 Fax: + 442078863259

E-mail: janeolver@aol.com

Received: 17 May 2002 Accepted in revised form: 7 October 2002

This work was presented as a poster at the Royal College of Ophthalmologists Annual Congress during 21-24

May 2002

The authors have no proprietary interest in this work 


\section{Methods}

We carried out a prospective study of consecutive patients undergoing primary DCR in 1997. All patients had epiphora from primary acquired nasolacrimal duct obstruction (PANDO). All surgery was performed by an oculoplastic trained ophthalmologist (JMO) while learning endonasal lacrimal surgery. In endonasal surgical DCR (EES-DCR), standard FESS instruments were used such as the Freer elevator, Blakesley forceps, with a keratome to incise the lacrimal sac mucosa. In EEL-DCR, the holmium:YAG laser was used exclusively, without assistance from surgical instruments other than the Freer elevator to displace the middle turbinate as necessary and to feel for small lacrimal bone fragments. Surgery was performed either under local anaesthesia or under general anaesthesia. Local anaesthesia consisted of topical amethocaine and injection of lignocaine $2 \%$ with adrenaline 1:200 000 to the medial eyelids, lacrimal fossa, and nasal mucosa. The nasal mucosa was also decongested with cocaine $4 \%$ and epinephrine 1:1000.

Surgical times, including the times of each step in the operation, were recorded for each case. External DCR had nine timed steps: (1) preparation of skin and drape, (2) skin-orbicularis incision to the anterior lacrimal crest, (3) osteotomy, (4) creation of nasal and lacrimal sac mucosal flaps, (5) suture posterior mucosal flaps, (6) pass and secure the silicone tubes, (7) suture anterior mucosal flaps, (8) close the wound and suture skin, and (9) dress the wound and undrape.

The EES-DCR had eight timed steps: (1) preparation of skin and drape, (2) preparation of nose including decongestant/local anaesthesia, (3) light pipe passed into lacrimal sac, (4) incise and excise nasal mucoperiosteum, (5) osteotomy, (6) incise lacrimal sac mucosa, (7) pass and secure the silicone tubes, and (8) pack the nose/undrape.

The EEL-DCR approach had seven timed steps: (1) preparation of skin and drape, (2) preparation of nose including decongestant/local anaesthesia, (3) light pipe passed into lacrimal sac, (4) laser ablation of nasal mucosa, (5) laser osteotomy and ablation of lower medial wall of lacrimal sac, (6) pass and secure the silicone tubes, and (7) undrape.

Not all steps were common to all three approaches; however, all patients had O'Donoghue silicone intubation for up to 3 months.

During bilateral cases, certain steps were common to both sides during the procedure, for example, draping and preparation, or final dressing. Surgical times for these steps were divided equally for each side, and for the purpose of statistical analysis, only one eye was chosen at random and included for each of these patients.
Postoperatively, patients were treated with 1 month's course of topical steroids and antibiotics (g.betnesol-N). A nasal steroid spray was only used if the surgeon noted excessive nasal mucosal inflammation. Broad-spectrum systemic antibiotics were used after all external DCR and only prescribed following the endonasal surgery if there was a mucocoele or history of previous acute dacryocystitis. Clinical evaluation during follow-up included the recording of symptoms, syringing and the FEDT. ${ }^{16,22,23}$ A positive FEDT was recorded if a drop of $2 \%$ fluorescein instilled in the conjunctival sac was seen to drain from the ostium on endoscopic nasal examination. Subjective and objective outcomes were assessed a minimum of 6 months after surgery.

\section{Statistical analysis}

Total surgical times were compared using analysis of variance (ANOVA). Contrasts were then used to compare (i) external and EES-DCR, and (ii) the average of these two techniques with EEL-DCR. Outcome measures of success were compared using Fisher's exact test.

Surgical steps of interest within each procedure, in particular, preparation and draping, and osteotomy, were analysed by the Kruskal-Wallis test and ANOVA, respectively. In bilateral cases, only one eye was chosen at random and included for each of these patients, in order that all subjects be independent.

\section{Results}

A total of 48 patients underwent 51 DCR procedures: 20 external, 16 EES-DCR, and 15 EEL-DCR. One patient underwent bilateral simultaneous EES-DCR and two patients underwent bilateral simultaneous EEL-DCR; therefore the results are for 48 procedures, 20 external DCR, 15 EES-DCR, and 13 EEL-DCR. There were 17 men and 31 women, mean age of 64 (range 18-90) years. The mean follow-up time with standard deviation for all three groups was $8.0 \pm 7.5$ (range 6-36) months. The mean follow-up for external DCR was $11 \pm 11$ (range 6-36) months, for EES-DCR $7 \pm 3.1$ (range 6-18) months, and for EEL-DCR $7 \pm 2.1$ (range 6-12) months.

A total of 30 procedures were for PANDO with simply epiphora, mucocoele (19), or recent dacryocystitis (two). Six cases had coexisting distal membranous commoncanalicular stenosis (external: four, EES-DCR: two).

In total, 50\% (8/16) EES-DCRs and 60\% (9/15) EEL-DCRs were performed under local anaesthesia. All other surgery (including bilateral surgery) was performed under general anaesthesia. No adverse events occurred during any procedure.

Table 1 shows the total mean surgical times for the 48 operations analysed and Table 2 shows a more detailed 
Table 1 Total mean surgical times. $N=48$ operations

\begin{tabular}{lccc}
\hline Type of surgery & $\begin{array}{c}\text { No. of } \\
\text { patients }\end{array}$ & $\begin{array}{c}\text { No. of } \\
\text { cases }\end{array}$ & $\begin{array}{c}\text { Mean } \\
\text { time (min) }\end{array}$ \\
\hline Primary external DCR & 20 & 20 & $41.1 \pm 10.3$ \\
Primary EES-DCR & 15 & 16 & $39.6 \pm 13.8$ \\
& & 15 & $40.1 \pm 14.1$ \\
Primary EEL-DCR & 13 & 15 & $20.9 \pm 7.8$ \\
& & 13 & $22.1 \pm 7.4^{\text {a }}$ \\
\hline
\end{tabular}

Figures in italics are for the purpose of statistical analysis, where in bilateral cases, only one eye was chosen at random and included for each of these patients.

EES-DCR = endoscopic endonasal surgical dacryocystorhinostomy, EEL-DCR = endoscopic endonasal laser dacryocystorhinostomy. ${ }^{a}$ EEL-DCR $v s$ average of external and EES-DCR, $P<0.001$.

account of times for each surgical step in all three groups. Comparing all the three procedures, there was a borderline difference in the total mean surgical times $(P=0.08)$. There was no difference between the time taken to perform external and EES-DCR $(P=0.79)$, whereby, external DCR took, on average, only $1 \mathrm{~min}$ longer (95\% confidence interval (CI): 6.6 min shorter to 8.5 min longer). EEL-DCR was clearly the quickest procedure $(P<0.001)$, approximately $18 \mathrm{~min}$ shorter than the average of external and EES-DCR (95\% CI: 11.3-25.8 min shorter).

Table 3 shows the postoperative follow-up outcome data (mean follow-up time $8.0 \pm 7.5$, range 6-36 months) for all three groups. Symptomatic success correlated well with irrigation findings and the positive functional endoscopic dye test.

\section{Outcomes of symptomatic success}

Symptomatic improvement was greatest for external DCR and showed the least improvement for EEL-DCR $(P=0.043)$. However, there was no significant difference between external and EES-DCR $(P=0.45)$. Follow-up data for symptomatic success were available for all except one patient (See Table 3).

\section{Outcome of objective success by syringing and FEDT}

A successful outcome with patency to syringing and a positive FEDT varied significantly between the three groups. External DCR was objectively the most successful and EEL-DCR the least, with respect to outcomes of patency to syringing $(P=0.007)$ and FEDT $(P=0.01)$. In the EES-DCR, 14 out of 16 procedures resulted in improved symptoms; however, only 12 out of 14 were patent to syringing, and only nine out of 12 of those patent to syringing had a positive FEDT. The data sets were incomplete for syringing and FEDT, and these outcomes are stated where performed (Table 3). All cases in which outcomes of syringing or FEDT were not stated, reported improved symptoms.

\section{Surgical failures}

The preoperative diagnoses of the unsuccessful cases are summarised in Table 4. The two EES-DCR cases that failed had been noted to have preoperative distal membranous common-canalicular stenosis. There were no consistent preoperative features in the failed EEL-DCR.

\section{Delaying surgical steps}

As a secondary analysis, the time required for preparation and draping was significantly less during EEL-DCR in comparison with EES-DCR $(4.5 \pm 4.4$ and $8.3 \pm 5.7 \mathrm{~min}$, respectively, $P=0.003$ ), and the greatest delays during external DCR were during skin incision, osteotomy $(P=0.03)$, and anterior and posterior flap formation (Table 2).

\section{Modelling analysis}

From these data, if six EEL-DCR, four EES-DCR, or three external DCRs are performed per operating list for a total of 45 lists per annum, the annual surgical throughput would be 270 EEL-DCR, 180 EES-DCR, and 135 external DCRs. Using the subjective success rates from this study, 162 EEL-DCR, 158 EES-DCR, and 128 external DCRs would be successful, and 108 EEL-DCR, 22 EES-DCR, and 7 external DCRs would fail. A proportion of those that fail would require further surgery. If $100 \%$ unsuccessful DCR operations had redo surgery by the same technique, the predicted number of additional operating lists required are shown in Table 5. Assuming that these lists would in turn produce a number of unsuccessful operations, even more lists would be required. Alternatively, the number of lists required in order to redo all the EEL-DCR failures by external DCR would be 36 lists, almost 1 year's operating capacity. The number of lists required to redo the EES-DCR failures by external DCR would be 7.3 lists.

\section{Discussion}

This study shows that by comparing the surgical times taken to perform DCR by three different approaches, external, EES, and EEL, an estimate of the surgical throughput can be made. Based on the clinical outcomes, we can use modelling analysis to predict the annual surgical throughput for a specialist service.

Both external and EES-DCR took similar times, while minimally invasive EEL-DCR was significantly faster, largely because it had the fewest steps. Unfortunately, EEL-DCR also had the worst outcomes.

Shun-Shin and Thurairajan ${ }^{9}$ reported an operating time for either primary or secondary EES-DCR of $30 \mathrm{~min}$ 
Table 2 Mean surgical times for each step during all procedures (including three bilateral cases)

\begin{tabular}{|c|c|c|c|c|c|c|c|c|c|c|}
\hline Type of surgery & & & & Mean surg & al times for each & tep during operation & $\min \pm S D)$ & & & \\
\hline $\begin{array}{l}\text { Primary } \\
\text { external }\end{array}$ & $\begin{array}{l}\text { Step } 1 . \\
\text { Preparation } \\
\text { and drape }\end{array}$ & $\begin{array}{l}\text { Step } 2 . \\
\text { Incise skin } \\
\text { to lacrimal fossa }\end{array}$ & $\begin{array}{l}\text { Step } 3 . \\
\text { Osteotomy }\end{array}$ & $\begin{array}{l}\text { Step } 4 . \\
\text { Create } \\
\text { mucosal flaps }\end{array}$ & $\begin{array}{l}\text { Step } 5 . \\
\text { Suture } \\
\text { posterior } \\
\text { mucosal flaps }\end{array}$ & $\begin{array}{l}\text { Step } 6 . \\
\text { Pass tubes } \\
\text { and secure } \\
\text { (tie or Ligaclips) }\end{array}$ & $\begin{array}{l}\text { Step } 7 . \\
\text { Suture } \\
\text { anterior } \\
\text { mucosal flaps }\end{array}$ & $\begin{array}{l}\text { Step } 8 . \\
\text { Close } \\
\text { wound and } \\
\text { suture skin }\end{array}$ & $\begin{array}{l}\text { Step } 9 . \\
\text { Dress } \\
\text { the wound }\end{array}$ & Total time \\
\hline 20 & $3.9 \pm 1.3$ & $8.05 \pm 5.3$ & $7.7 \pm 3.0$ & $4.5 \pm 1.9$ & $4.6 \pm 2.4$ & $5.8 \pm 3.3$ & $4.3 \pm 1.3$ & $3.8 \pm 1.2$ & $1.6 \pm 0.8$ & $41.1 \pm 10.3$ \\
\hline $\begin{array}{l}\text { Primary } \\
\text { EES-DCR }\end{array}$ & $\begin{array}{l}\text { Step } 1 . \\
\text { Preparation } \\
\text { and drape }\end{array}$ & $\begin{array}{l}\text { Step } 2 . \\
\text { Prep. inject nose }\end{array}$ & $\begin{array}{l}\text { Step } 3 . \\
\text { Light } \\
\text { pipe in }\end{array}$ & $\begin{array}{l}\text { Step } 4 . \\
\text { Incise } \\
\text { nasal mucosa }\end{array}$ & $\begin{array}{l}\text { Step } 5 . \\
\text { Osteotomy }\end{array}$ & $\begin{array}{l}\text { Step } 6 . \\
\text { Open } \\
\text { lacrimal mucosa }\end{array}$ & $\begin{array}{l}\text { Step } 7 . \\
\text { Pass tubes } \\
\text { and secure } \\
\text { (tie or Ligaclips) }\end{array}$ & $\begin{array}{l}\text { Step } 8 . \\
\text { Pack the } \\
\text { nose/undrape }\end{array}$ & Total time & \\
\hline $\begin{array}{l}16 \\
(15)\end{array}$ & $\begin{array}{l}7.9 \pm 5.7 \\
8.3 \pm 5.7\end{array}$ & $\begin{array}{l}4.2 \pm 3.0 \\
4.1 \pm 3.0\end{array}$ & $\begin{array}{l}2.3 \pm 0.4 \\
2.3 \pm 0.5\end{array}$ & $\begin{array}{l}6.0 \pm 5.4 \\
6.2 \pm 5.6\end{array}$ & $\begin{array}{l}6.4 \pm 3.6 \\
6.5 \pm 3.6\end{array}$ & $\begin{array}{l}7.3 \pm 4.6 \\
7.3 \pm 4.7\end{array}$ & $\begin{array}{l}6.2 \pm 4.6 \\
6.4 \pm 4.7\end{array}$ & $\begin{array}{l}2.9 \pm 2.5 \\
3.1 \pm 2.6\end{array}$ & $\begin{array}{l}39.6 \pm 13.8 \\
40.1 \pm 14.1\end{array}$ & \\
\hline $\begin{array}{l}\text { Primary } \\
\text { EEL-DCR }\end{array}$ & $\begin{array}{l}\text { Step } 1 . \\
\text { Preparation } \\
\text { and drape }\end{array}$ & $\begin{array}{l}\text { Step } 2 . \\
\text { Prep. inject nose }\end{array}$ & $\begin{array}{l}\text { Step } 3 . \\
\text { Light } \\
\text { pipe in }\end{array}$ & $\begin{array}{l}\text { Step } 4 . \\
\text { Laser } \\
\text { nasal mucosa }\end{array}$ & $\begin{array}{l}\text { Step 5. Laser } \\
\text { osteotomy } \\
\text { lacrimal sac } \\
\text { mucosa }\end{array}$ & $\begin{array}{l}\text { Step } 6 . \\
\text { Pass tubes } \\
\text { and secure } \\
\text { (tie or Ligaclips) }\end{array}$ & $\begin{array}{l}\text { Step } 7 . \\
\text { Dress } \\
\text { the wound }\end{array}$ & Total time & & \\
\hline $\begin{array}{l}15 \\
(13)\end{array}$ & $\begin{array}{l}4.3 \pm 4.2 \\
4.5 \pm 4.4\end{array}$ & $\begin{array}{l}4 \pm 4.1 \\
4.3 \pm 4.4\end{array}$ & $\begin{array}{l}4.3 \pm 3.7 \\
4.7 \pm 3.8\end{array}$ & $\begin{array}{l}3.7 \pm 1.5 \\
3.7 \pm 1.5\end{array}$ & $\begin{array}{l}4.4 \pm 2.7 \\
4.6 \pm 2.8\end{array}$ & $\begin{array}{l}4.3 \pm 2.0 \\
4.2 \pm 2.0\end{array}$ & $\begin{array}{l}1 \pm 0 \\
1 \pm 0\end{array}$ & $\begin{array}{l}20.9 \pm 7.8 \\
22.1 \pm 7.4\end{array}$ & & \\
\hline
\end{tabular}

See Table 1 footnote. 
Table 3 Postoperative outcome data at mean follow-up of $8.0 \pm 7.5$ (range $6-36$ ) months. $N=48$ operations

\begin{tabular}{lcrrr}
\hline Type of surgery & $\begin{array}{c}\text { No. of } \\
\text { DCRs }\end{array}$ & $\begin{array}{c}\text { Symptomatic } \\
\text { success }^{\mathrm{a}}\end{array}$ & $\begin{array}{c}\text { Patent to } \\
\text { syringing }^{\mathrm{b}}\end{array}$ & $\begin{array}{r}\text { Positive } \\
\text { FEDT }\end{array}$ \\
\hline Primary external DCR & 20 & $18 / 19(95 \%)$ & $19 / 19$ & $16 / 16$ \\
Primary EES-DCR & 16 & $14 / 16(88 \%)$ & $12 / 15$ & $9 / 15$ \\
& 15 & $13 / 15(87 \%)$ & $11 / 14$ & $9 / 14$ \\
Primary EEL-DCR & 15 & $9 / 15(60 \%)$ & $9 / 15$ & $9 / 15$ \\
& 13 & $8 / 13(62 \%)$ & $8 / 13$ & $8 / 13$ \\
\hline
\end{tabular}

See Table 1 footnote.

${ }^{\mathrm{a}} P=0.043,{ }^{\mathrm{b}} P=0.007,{ }^{\mathrm{c}} P=0.01$.

Table 4 Unsuccessful cases and preoperative diagnosis. $N=9$

\begin{tabular}{lcl}
\hline Type of surgery & $\begin{array}{c}\text { Number of } \\
\text { unsuccessful } \\
\text { operations }\end{array}$ & \multicolumn{1}{c}{$\begin{array}{c}\text { Preoperative } \\
\text { diagnosis }\end{array}$} \\
\hline $\begin{array}{l}\text { Primary external DCR } \\
\text { Primary EES-DCR }\end{array}$ & 1 & PANDO (1) \\
PANDO + distal \\
membranous \\
common-canalicular \\
disease (2) \\
PANDO (2), \\
mucocoele (3), \\
Recent dacryocystitis (1)
\end{tabular}

Table 5 Predicted number of additional operating lists required to reoperate on unsuccessful DCR using the original technique

\begin{tabular}{lcccc}
\hline $\begin{array}{l}\text { Type of } \\
\text { surgery }\end{array}$ & $\begin{array}{c}\text { Number } \\
\text { of cases } \\
\text { per list }\end{array}$ & $\begin{array}{c}\text { Number } \\
\text { that could } \\
\text { be operated } \\
\text { per annum } \\
\text { if } 45 \text { lists }\end{array}$ & $\begin{array}{c}\text { Ratio } \\
\text { success/ } \\
\text { failure }\end{array}$ & $\begin{array}{c}\text { Number of } \\
\text { additional } \\
\text { lists required for } \\
\text { failures - using } \\
\text { same surgical } \\
\text { technique if 100\% } \\
\text { reoperated (if only } \\
75 \% \text { reoperated) }\end{array}$ \\
\hline External DCR & 3 & 135 & $128 / 7$ & $2.3(2.0)$ \\
EES-DCR & 4 & 180 & $158 / 22$ & $5.5(4.0)$ \\
EEL-DCR & 6 & 270 & $162 / 108$ & $18(13.5)$ \\
\hline
\end{tabular}

and Hehar et al $20 \mathrm{~min}$ for EEL-DCR using the Holmium:YAG laser. The oculoplastic surgeon (JMO) performing the endonasal lacrimal surgery in this study (timings made in 1997) was learning endolacrimal surgery at the time; we postulate that with increased experience, these times would be reduced.

One reason that external DCR takes the longest time to perform is that it has the greatest number of steps nine - and lengthy time for suturing the posterior and anterior mucosal flaps. In EES-DCR and EEL-DCR, the nasal and lacrimal mucosa are either incised/excised or ablated but sutured. The osteotomy in external DCR and also in many cases of EES-DCR includes the removal of part of the thick ascending process of the maxilla and is larger than for EEL-DCR, therefore takes longer to fashion. In EEL-DCR, mainly the thin lacrimal bone is ablated, which is quite rapid. In EEL-DCR, the laser applied to the bone also opens the lacrimal sac, and therefore this is measured as one step, further contributing to its smaller number of steps (seven).

Symptomatic success rates significantly varied among the three groups. The results of primary external DCR (95\%) in this study support the reported success rates for external DCR of between 80 and 99\%. ${ }^{17-21}$ However, the presence of a cutaneous scar and the potential for injury to structures during the approach, cerebrospinal fluid (CSF) rhinorrhoea and postoperative morbidity, have fuelled the popularity of less invasive endonasal approaches. In addition, the advantage of a lack of scar, endonasal DCR also provides the opportunity to address coexistent nasal pathology, for example, a deviated nasal septum or concha bullosa. Its disadvantages include a lower success rate, smaller rhinostomy, and difficulty to identify tumours in the sac. Primary endonasal-surgical DCR has been reported to have a success rate of between 83 and $86 \% .{ }^{14,6,9,10,16,24}$ In this study, $88 \%$ achieved symptomatic success.

The use of laser to create the rhinostomy during endonasal DCR became popular since its description using an argon laser in $1990 .^{2}$ EEL-DCR is often performed as day-case surgery under local anaesthesia using the holmium:YAG or the KTP laser., ${ }^{3,5,7,11,16}$ Advantages of EEL-DCR over EES-DCR include even less blood loss during surgery and shorter operating time. These advantages make EEL-DCR suitable, for example, for the frail elderly patient, who otherwise might not be fit for longer lacrimal surgery, either under local or under general anaesthesia. Primary EEL-DCR with intubation has been reported to have a success rate of $70 \%$ beyond 6 months. ${ }^{11,16}$ However, Sadiq et al later acknowledged that this figure could be as low as $64 \%$ when taking into account patients lost to follow-up. In this small series of 'learning curve' cases, we only achieved a success rate of $60 \%$ ( $62 \%$ overall), but in later cases improved to $70 \% .^{16}$

EEL-DCR was the quickest procedure to perform, with a mean operating time of 21 min compared to 40 and $41 \mathrm{~min}$ for EES-DCR and external DCR, respectively. We calculated that over a year, twice as many EEL-DCR would be performed compared to external DCRs (270 vs 135); however, a significantly greater number of these would fail (108 vs 7), and a proportion of these would require further surgery. If we apply the success rate of $70 \%^{16}$ rather than $60 \%$ to our surgical times for EEL-DCR, when 270 procedures are performed in 1 year, 189 rather than 162 would be successful. In all, 81 rather than 108 
would fail, which still represents a large number of patients potentially requiring redo surgery. This reduces the benefit of a greater initial throughput. In addition, there is the distress caused to the patients following an unsuccessful procedure as well as the frustration felt by clinicians surrounding waiting list issues and limited resources.

Surgeons should be aware that although endonasal lacrimal surgery appears to have a greater throughput, the high number of failures for EEL-DCR compared to EES-DCR make holmium:YAG laser lacrimal surgery a poor choice. Patients who want minimally invasive surgery under local anaesthesia and who understand that the success rate of EEL-DCR is lower than for EES-DCR and external DCR may opt for laser surgery. By limiting the extent of tissue lasered and using surgical instruments, for example a keratome, to open the lacrimal sac (laser-assisted surgery), or applying antimetabolites such as mitomycin C, success rates may be improved. ${ }^{13-15,25}$ The role of antimetabolites to decrease the fibrosis associated with secondary intention healing has still to be established. ${ }^{13-25}$

We have compared the time taken to perform DCR by three different approaches. Based on the outcomes, we have summarised the merits and limitations of each technique. The lower success rate of EEL-DCR may negate the apparent benefit from its greater surgical throughput. Since the throughput of a specialist lacrimal service is dependent on the number of cases that can be performed per operating list, it is important to consider the time taken to perform these procedures and their outcomes. Patients wanting endonasal DCR should consider the merits of EES-DCR compared to EEL-DCR.

\section{References}

1 McDonogh M, Meiring JH. Endoscopic transnasal dacryocystorhinostomy. J Laryngol Otol 1989; 103: 585-587.

2 Massaro BM, Gonnering RS, Harris GJ. Endonasal laser dacryocystorhinostomy. A new approach to nasolacrimal duct obstruction. Arch Ophthalmol 1990; 108: 1172-1176.

3 Woog JJ, Metson R, Puliafito CA. Holmium:YAG endonasal laser dacryocystorhinostomy. Am J Ophthalmol 1993; 16: $1-10$.

4 Whittet HB, Shun-Shin GA, Awdry P. Functional endoscopic transnasal dacryocystorhinostomy. Eye 1993; 7: 545-549.

5 Boush GA, Bradley NL, Dortzbach RK. Results of endonasal laser-assisted dacryocystorhinostomy. Ophthalmology 1994; 101: 955-959.
6 Watters GWR, Whittet HB, Shun-Shin GA, Milford CA. Endoscopic transnasal dacryocystorhinostomy-long term results. Minim Invas Ther Allied Technol 1996; 5: 505-510.

7 Sadiq SA, Hugkulstone CE, Jones NS, Downes RN. Endoscopic holmium:YAG laser dacryocystorhinostomy. Eye 1996; 10: 43-46.

8 Hehar SS, Jones NS, Sadiq SA, Downes RN. Endoscopic holmium:YAG laser dacryocystorhinostomy - safe and effective as a day-case procedure. J Laryngol Otol 1997; 111(11): 1056-1059.

9 Shun-Shin GA, Thurairajan G. External dacryocystorhinostomy - an end of an era? Br J Ophthalmol 1997; 81: 716-717.

10 Yung MW, Hardman-Lea S. Endoscopic inferior dacryocystorhinostomy. Clin Otolaryngol 1998; 23: 152-157.

11 Sadiq SA, Ohrlich S, Jones NS, Downes RN. Endonasal laser dacryocystorhinostomy - medium term results. $\mathrm{Br} \mathrm{J}$ Ophthalmol 1997; 81(12): 1089-1092.

12 Von Arx G, Sadiq SA, Downes RN. Endonasal laser dacryocystorhinostomy. Br J Ophthalmol 1998; 82: 976.

13 Zilelioglu G, Ugurbas SH, Anadolu Y. Adjunctive use of mitomycin $\mathrm{C}$ on endoscopic lacrimal surgery. $\mathrm{Br} \mathrm{J}$ Ophthalmol 1998; 82: 63-66.

14 Szubin L, Papageorge A, Sacks E. Endonasal laser assisted dacryocystorhinostomy. Am J Rhinol 1999; 13: 371-374.

15 You Y, Fang C. Intraoperative mitomycin C in dacryocystorhinostomy. Ophthalmic Plast Reconstr Surg 2001; 17: 115-119.

16 Moore WM, Bentley CR, Olver JM. Functional and anatomic results following two types of endoscopic endonasal dacryocystorhinostomy, surgical and holmium laser. Ophthalmology 2002; 109: 1575-1582.

17 Caldwell GW. Two new operations for obstruction of the nasal duct with preservation of the canaliculi and an incidental description of a new lacrimal probe. NY Med J 1893; 57: 581.

18 Welham RAN, Henderson PH. Results of dacryocystorhinostomy: analysis of failure. Trans Ophthalmol Soc UK 1973; 93: 601-609.

19 Welham RAN. Investigations for patients undergoing lacrimal surgery. Eye 1998; 12: 334-336.

20 Rosen N, Sharir M, Moverman DC, Rosner M. Dacryocystorhinostomy with silicone tubes: evaluation of 253 cases. Ophthalmic Surg 1989; 20: 115-119.

21 Tarbet KJ, Custer PL. External dacryocystorhinostomy: surgical success, patient satisfaction, and economic cost. Ophthalmology 1995; 102: 1065-1070.

22 Olver JM, Minasian M. Nasal endoscopy for ophthalmologists. CME J Ophthalmol 1998; 2: 73-77.

23 Minasian $M$, Olver JM. The value of nasal endoscopy after dacryocystorhinostomy. Orbit 1999; 18: 167-176.

24 Jokinnen K, Karja J. Endonasal dacryocystorhinostomy. Arch Otolaryngol 1974; 100: 41-44.

25 Camera JG, Bengzon AU, Henson RD. The safety and efficacy of mitomycin $C$ in endonasal endoscopic laserassisted dacryocystorhinostomy. Ophthalmic Plast Reconstr Surg 2000; 16: 114-118 